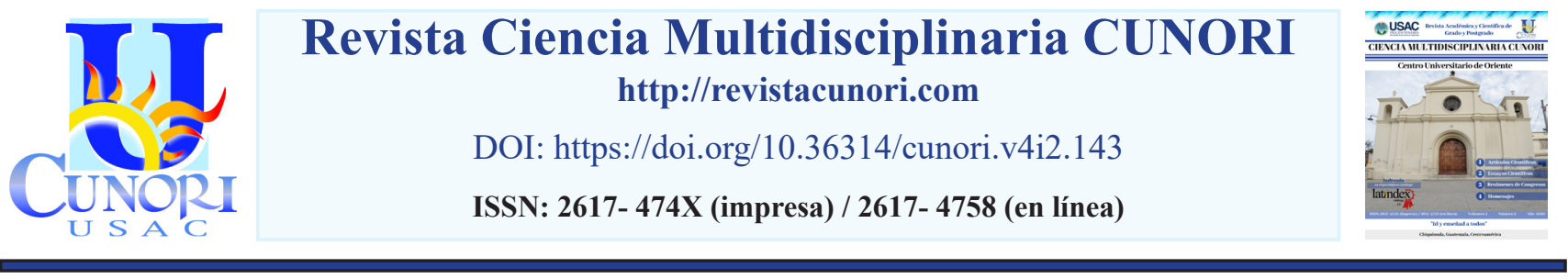

Referencia del homenaje

Mosquera-Saravia M. T. (2020). Homenaje a Rafael Girard: el etnógrafo de la cosmovisión maya. Revista Ciencia Multidisciplinaria Cunori, 4(2), 179-183. https://doi.org/10.36314/cunori.v4i2.143

\title{
Homenaje a Rafael Girard: el etnógrafo de la cosmovisión maya
}

\section{Tribute to Rafael Girard: the Ethnographer of the Mayan Worldview}

\author{
María Teresa Mosquera Saravia \\ Instituto de Estudios Interétnicos y de los Pueblos Indígenas, Universidad de San Carlos de Guatemala \\ https://orcid.org/0000-0003-0924-0302 \\ Recibido: 18 de mayo de 2020 / Revisado: 20 de mayo de 2020 / Aceptado: 29 de julio de 2020
}

Disponible en internet el 30 de octubre de 2020

*Autor para correspondencia.

Correo electrónico: teresa.mosquera@usac.edu.gt

Resumen

D afael Girard fue un etnógrafo que vivió 30 años en el área Chortí de Guatemala, fue sin duda uno de los primeros etnógrafos Len legitimar un importante acervo cultural de fotografías y películas sobre la cosmovisión maya en el cual explica todos los mitos y los ritos Chortís referidos al ciclo agrícola, a las ceremonias del año nuevo maya, el inicio de la temporada de lluvias, el inicio de las siembras con sus respectivos ritos de fecundidad de la tierra, etc. El municipio de Jocotán, en Chiquimula le ha hecho un homenaje por medio de un busto que se localiza a un costado de la iglesia en el parque central. En pocas palabras se explica la importancia de sus hallazgos respecto de la cultura Chortí en particular y de la maya en general, se escriben estas palabras con la intensión de reconocer su legado.

Palabras clave: etnografía guatemala cosmovisión chortís

Abstract

D afael Girard was an ethnographer who lived 30 years in the Chortí area of Guatemala, was undoubtedly one of the first eth- nographers to legitimize an important cultural heritage of photographs and films about the Mayan worldview in which he explains all the myths and Chortís rites related to the agricultural cycle, to the Mayan New Year ceremonies, the beginning of the rainy season, the beginning of sowing with their respective rites of fertility of the land, etc. The municipality of Jocotán, in Chiquimula has paid homage to him through a bust located at the side of the church in the central park. In a few words it explains the importance of his findings regarding the Chortí culture in particular and the Maya in general, these words are written with the intensity of recognizing his legacy.

Keywords: ethnography guatemala worldview chortís 


\section{Rafael Girard}

La vida de Rafael Girard es sumamente interesante, nació en Suiza en el año 1898, a los 21 años fue aceptado en la Sociedad de Geografía e Historia de Paris. Decidió viajar a Honduras con la idea de fundar en aquel lugar la Sociedad de Geografía e Historia y realizar estudios etnográficos de algunos de los grupos indígenas de la región. Comenzó a trabajar en la compañía bananera Cuyamel Fruit Company, a los 37 años de edad obtuvo el título de Ingeniero Eléctrico, debido a que su interés principal fueron los indígenas Chortís, debió resolver, una forma de financiar su estancia e investigaciones, para ello hizo diversas gestiones (préstamos y ahorros) para constituir una empresa propia de energía eléctrica en Copán, Honduras; Quetzaltepeque y Esquipulas, Guatemala. Una vez resuelta su situación económica decidió dedicar su vida al estudio de los indígenas Chortís.

¿Por qué Rafael Girard merece un homenaje? Permaneció en territorio Chortí durante treinta años, en ese tiempo hizo trabajo de campo entrevistando a ciento cinco informantes, entre hombres y mujeres, en dieciséis localidades: Quetzaltepeque, Chiquimula, Santa Rosalía, Laguna de Cayur, Tutikopote, E1 Amatillo, Tanshá, Tashajté, Tunucó, Copán, Nochán, Jocotán, Camotán, Limón, Olopa, La Ladrillera.

Figura No. 1 Comunidades del municipio en las que trabajó Girard.

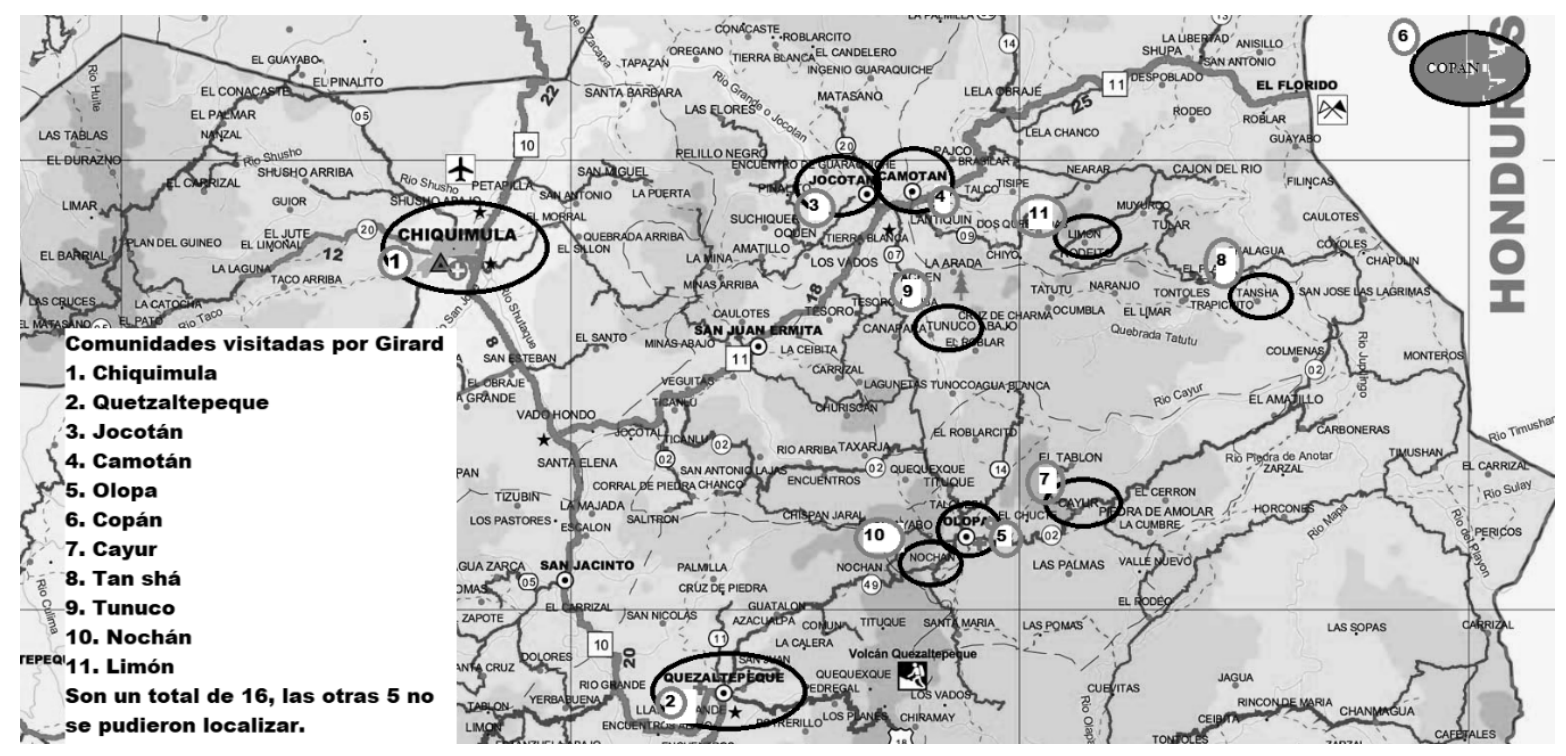

Fuente: Mosquera-Saravia. Mapa tomado de Google map.

Su larga estancia en aquellas tierras, fue reconocida con un homenaje en el municipio de Jocotán por medio de un busto, colocado en el parque central de la localidad, a un costado de la iglesia. Se puede decir que en Guatemala es difícil localizar en los diversos municipios del territorio un homenaje destinado a un científico social, no es aventurado afirmar que es el único que existe al menos en el área rural. 
Figura No. 2 Busto de Rafael Girard en el parque del municipio de Jocotán, Chiquimula.

Fuente: Méndez-Vásquez (2020).

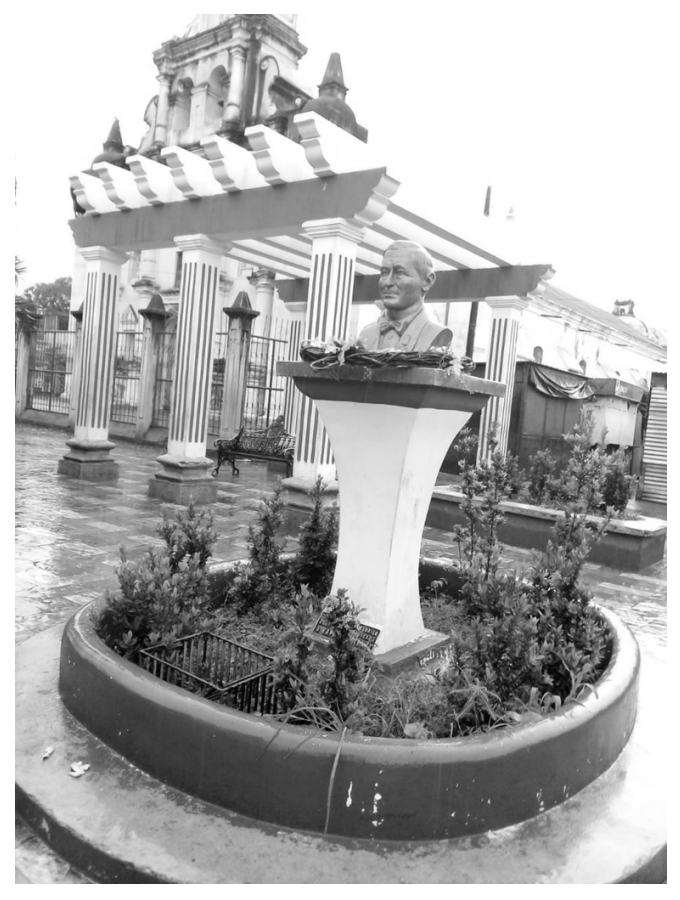

Sus descubrimientos y aportes, se dieron a conocer por medio de la publicación de una veintena de libros (Todas sus publicaciones se incluyen en la bibliografía de este homenaje). entre las décadas de los años cuarenta hasta los setentas, fue reconocido también por su participación en los congresos internacionales de americanistas, muy de boga durante aquellas décadas. Todas sus publicaciones y conferencias le sitúan como uno de los referentes respecto a la cosmovisión maya, concretamente en las temáticas: espacio/tiempo, dioses, ciclos agrícolas, mitos y ritos. Compartió mesas y discusiones con los académicos mexicanos Alfonso Villa Rojas, Alberto Ruz Lhuillier, Calixta Guiteras Holmes, y con los estadounidenses Robert Redfiel, Eric Thompson, para mencionar algunos.

En Guatemala, durante esos años estaban presentes investigadores estadounidenses (Benjamín Paul, Robert Redfield, Sol Tax, Charles Widson, etc.) que vinieron a realizar estudios etnográficos y se aglutinaron de una u otra forma en la institución llamada: Instituto Indigenista Nacional, en esa misma institución se creó el Seminario de Integración Social Guatemalteca, con la intensión de publicar una colección de libros, que tenían como eje estructurador la problemática indígena de Guatemala.

La colección completa del seminario, tiene una gran diversidad de autores y temas, pero ninguno de éstos libros profundizó la temática de la cosmovisión maya, como lo hizo Rafael Girard, en sus palabras explica: "Lo expuesto acerca de la existencia de dos tipos de culto, uno diurno y otro nocturno, explica que la mayoría de los etnógrafos sólo hayan podido apreciar aspectos del primero, que se realiza en iglesias, a la vista del público. Por mi parte he tenido la excepcional oportunidad de presencia los ritos indígenas, principalmente los del segundo culto, gracias a prolongadas investigaciones, que me permitieron contar con la confianza de los pluviomagos, y no sólo presenciar los ritos nocturnos sino también 
filmarlos y fotografiarlos." (Girard,1966:65), fue así que con la publicación de más de veinte libros sobre el tema, podemos concluir diciendo que Rafael Girard es el primer etnógrafo que escribe sobre la cosmovisión maya en el territorio guatemalteco.

Hoy en día los Ajq'uijab' han heredado de generación en generación todas las prácticas del rito y la ceremonia, ellos las valoran y enseñan, pero queda fuera de su alcance hacer un análisis entre el pasado histórico y la significación del mito. El trabajo de campo, que hizo Rafael Girard entre los Chortís, genera especialmente en nuestros días, diversas explicaciones sobre ese nexo y da respuesta a la pregunta del ¿por qué? de esas ceremonias y ritos. Al respecto indica en uno de sus libros: "En la manera de pensar y de expresarse del indígena, así como en sus actuaciones rituales, es evidente la supervivencia de tradiciones precolombinas, aún a través de su aparente devoción a santos católicos. Esta apreciación se fundamenta, no sólo en las explicaciones de los sacerdotes aborígenes de diferentes localidades, que por sí mismas ponen de manifiesto la existencia de un fenómeno religioso-social general, sino también en los paralelismos que ofrecen estos rasgos vigentes con los contenidos en fuentes arqueológicas, códices y crónicas coloniales" (Girard, 1966:56). Para los interesados en la temática de la cosmovisión maya, recomiendo la lectura de las publicaciones de Rafael Girard tituladas: Los mayas; su civilización, su historia, sus vinculaciones continentales (1966) y Los Chortís ante el problema maya (1949).

Finalmente, consideramos que para valorar el intelecto de Girard, la lectura de alguna de sus publicaciones es necesaria, muy probablemente sus documentos sean poco conocidos en Guatemala, por ello también recomiendo al CUNORI y su revista, la publicación de alguno de sus documentos. Además, es justo mencionar que el aporte al conocimiento sobre nuestro pasado y presente mesoamericano lo debemos a personas como Rafael Girard quienes dedicaron su vida al estudio de los pueblos indígenas.

\section{Referencias}

Girard, R. (1947). Génesis y función de la Greca escalonada. México: s. ed.

Girard, R. (1948). El Calendario maya-mexica: origen, función, desarrollo y lugar de procedencia. México: Editorial Stylo.

Girard, R. (1948). Esoterismo en el Popol Vuh. México: Editorial Stylo.

Girard, R. (1949). Algunos caracteres psicológicos de los Chortís - Honduras. México: s. ed.

Girard, R. (1949). Los Chortís ante el problema Maya: historia de las culturas indígenas de América, desde su origen hasta hoy. México: Antigua Librería Robredo.

Girard, R. (1951). Historia del origen y desarrollo de las culturas indoamericanas. México: Antigua Librería Robredo.

Girard, R. (1951). Refutación de una crítica a "Los Chortís ante el problema Maya". México: s. ed.

Girard, R. (1952). El popol -vuh fuente histórica. Guatemala: Ed. Ministerio de Educación Pública.

Girard, R. (1954) Le popol vuh, historie culturelle des Maya-Quiché. Editorial Payot, Paris. 
Girard, R. (1955) Correlación entre mitos, ritos actuales y arqueología maya. s. 1. s. ed.

Girard, R. (1955) Réplica a la crítica de Heinrich Berlin sobre “El Popol Vuh, fuente histórica”. s. 1., s. ed.

Girard, R. (1958) Indios selváticos de la Amazonía peruana. México: Mex. Editores.

Girard, R. (1958) Guatemala en el XXXIII Congreso Internacional de Americanistas. Guatemala: Ministerio de Educación Pública de Guatemala.

Girard, R. (1959) El colapso maya y los nahuas. México: s. ed.

Girard, R. (1960). La Civilización maya y sus epigonales. Guatemala: imprenta Latina.

Girard, R. (1962) Los Mayas eternos. México: Antigua Librería Robredo.

Girard, R. (1966) Los mayas: su civilización, su historia, sus vinculaciones continentales. México: Libro Mex. Editores.

Girard, R. (1968) La misteriosa cultura olmeca: últimos descubrimientos de esculturas pre Olmecas en el municipio: La Democracia. Guatemala: s. ed.

Girard, R. (1969) El colapso maya y los nahuas. México: Impresiones modernas.

Girard, R. (1976) Historia de las civilizaciones antiguas de América : desde sus orígenes. México: Hyspamerica ediciones, editores mexicanos unidos

Girard, R. (1977) Origen y desarrollo de las civilizaciones antiguas de América. México: Editores mexicanos unidos.

\section{Sobre la autora}

\section{María Teresa Mosquera Saravia}

Antropóloga del Instituto de Estudios Interétnicos y de los Pueblos Indígenas de la Universidad de San Carlos de Guatemala.

Copyright (c) María Teresa Mosquera Saravia

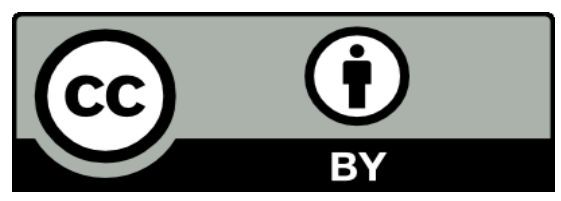

Este texto está protegido por una licencia CreativeCommons 4.0.

Usted es libre para compartir, copiar y redistribuir el material en cualquier medio o formato y adaptar el documento, remezclar, transformar y crear a partir del material para cualquier propósito, incluso comercialmente, siempre que cumpla la condición de atribución: usted debe reconocer el crédito de una obra de manera adecuada, proporcionar un enlace a la licencia, e indicar si se han realizado cambios. Puede hacerlo en cualquier forma razonable, pero no de forma tal que sugiera que tiene el apoyo del licenciante o lo recibe por el uso que hace. 